The Israeli Journal of Aquaculture - Bamidgeh, IJA.73.2021.1370552, 6 pages

CCBY-NC-ND-4.0 • https://doi.org/10.46989/001c.21408

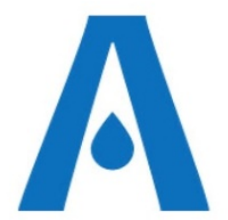

The $I J A$ is a peer-reviewed open-access, electronic journal, freely available without charge to users

Produced by the AquacultureHub non-profit Foundation Sale of IJA papers is strictly forbidden

\title{
Forty years of fluctuation in the occurrence of two various metazoan parasites: Contracaecum multipapillatum (Nematoda) and Digenean metacercaria N1 in warm water fish culture in the Israeli farms
}

\author{
Margarita Smirnov*, Tamir Ofek, Tetsuzan Benny Ron \\ Central Fish Health Laboratory, Department of Fisheries and Aquaculture, Ministry of \\ Agriculture and Rural Development, Nir David, 1080300 Israel
}

Key words: parasites, digenean metacercaria, parasitic nematode, management

\begin{abstract}
We present field observation results from October 2019 to February 2021 in Israeli fish farms. Surprisingly, two metazoan parasites, the larvae of Contracaecum multipapillatum and unidentified metacercaria N1, which disappeared from Israeli fish farming 30 years ago, were commonly found in the current study. The reappearance of these two helminths is likely related to changes in the management policy related to new regulations regarding bird-of-prey species. It means that farmers could have prevented parasitic infections by keeping away piscivorous birds from their fish ponds and by treating these ponds with appropriate compounds against the affected invertebrates.
\end{abstract}

\footnotetext{
* Corresponding author. E-mail: Ritas@moag.gov.il
} 


\section{Introduction}

The distribution of various fish parasites in warm water aquaculture is high. Numerous parasitic fauna investigations were carried in 1960-2016 in Israel (Paperna, 1964; Landsberg, 1988; Djikowski et al., 2003; Falk et al., 2020). The examination of various cultured fish during all stages of their production process is a constant part of the routine work of the Central Fish Health Laboratory (CFHL). It has great importance for the management policy in the fish farming systems. During such routine examination, two types of helminths that belong to different groups (subclass Digenea and phylum Nematoda) were found.

Life cycles of the parasitic nematodes and most digenean flukes included two intermediate hosts and a definite host. In Israeli fish ponds, small crustacean Cyclops (subclass Copepoda) is the first intermediate host of Contracaecum multipapillatum and pelicans (Pelecanus onocrotalus) were definitive hosts of this nematode (Landsberg, 1988, Paperna 1991, Landsberg, unpublished data). For the digenean parasite, the first intermediate hosts were mollusk species (genus Pseudoplotia scabra or Melanoides tuberculata), and the final ones were piscivorous birds such as pelicans and cormorants. Both these helminths use fish as a second intermediate host.

The parasites of these types are dispersed all over the world. Researchers from Egypt (Younis et al., 2017), Mexico (Valles-Vega et al., 2017), Colombia (Castellanos et al., 2017), Russia (Pronkina and Spiridonov, 2020), Ethiopia (Amare et al., 2014), Turkey (Pekmezci and Yardimci, 2019), Australia (Lambery et al., 2002; Shamsi et al., 2008) found these parasites in different fish species affecting their various organs.

This article presents the results of our field studies collected from different fish farms from 2019 to 2020.

Case 1: Beginning from October 2019 until February 2021, tilapia samples were examined before marketing. Hybrid tilapia (Oreochromis aureus $X$ Oreochromis niloticus) weighed $500-600 \mathrm{gr}$ and did not show any diseases. Contracaecum multipapillatum larvae were found in fish from several farms located in Beit She'an Valley and by the Mediterranean Sea.

Case 2: Before transferring them to the fish farms by the hatcheries, tilapia fingerlings (Oreochromis aureus $X$ Oreochromis niloticus) and mullet (Mugil cephalus) were examined during July 2020. Some of the fingerlings were weak and exhausted. Numerous digenean metacercaria type 1 were revealed in their liver.

Parasitological examination

\section{Materials and Methods}

Fish were anesthetized with phenoxyethanol, measured, and weighed to determine the condition factor (CF). The condition factor of each fish was calculated according to the Fulton formula:

\section{$\mathrm{CF}=(\mathrm{m} / \mathrm{L} 3) \times 100$}

Where:

$\mathbf{m}$ represents weight (gr) while $\mathbf{L}$ represents the total length, from the fish mouth to the fork end of the caudal fin).

Gills, skin, liver, spleen, kidney, intestine, heart, and flesh were examined for the presence of ecto- and endo-parasites with light microscopy (Noga, 1996). Parasites were collected and processed according to routine procedures (Paperna I,1974).

Case 1: Released nematodes were examined alive or after fixation in hot $4 \%$ formalin or $70 \%$ alcohol were cleared in Lactophenol for $24 \mathrm{~h}$. or in $1 \%$ glycerin (Paperna, 1996).

Case 2: Metacercariae were isolated from their cysts in the liver by applying pressure. Fixation was done with $70 \%$ alcohol, and then staining of metacercaria was performed with hematoxylin.

For identification of helminths, specimens were checked morphologically by light microscopy and measured with a micrometer eyepiece. Results were compared with those previously published by Paperna (1964, 1974, 1996). 


\section{Results}

Case 1: $~ 550$ fish were sampled after finding the parasitic nematode, the Contracaecum species. Parasites were found only in tilapia. The nematode larvae were not encysted and were located free in the pericardial cavity with up to 12 worms (Figure 1). The Contracaecum larvae reached a size of $4-6 \mathrm{~cm}$ and 2-3 $\mathrm{mm}$ in diameter. Living larvae had pink-white color. The body was long, its anterior part round, and the tail was blunt. The esophagus was longer than the caecum, and the anal opening was near the posterior body's end (Figure $\mathbf{2} \mathbf{b}, \mathbf{c}$ ). No noticeable pathological signs were seen in the external appearance and inner organs of the fish. The condition factor (CF) of the examined fish with and without the parasites was $2.7-2.8$, indicating that the helminths do not affect fish health status.

Case 2: Digenean metacercaria infection was found in the liver of tilapia fingerlings and one-yearold mullet (Mugil cephalus) during the summer of 2020. The infection's extensity was various, with an average number of parasites from two to 30 per fish. The weight of hybrid tilapia was $0.5-1.5$ gr, and the CF was 1.01, while many fish were weak. The mullet were robust, and their average weight was 20-40 gr. Cysts of metacercaria in the fish liver were $0.4-0.5 \mathrm{~mm}$ in diameter (Figure 3). Metacercaria was $0.8 \mathrm{~mm}$ long, $0.17-0.2 \mathrm{~mm}$ wide. Two stems of the excretory vesicles unit into one trunk in the posterior body (Figure $\mathbf{3} \mathbf{~ b}$ ). After several months, the dying flukes caused the fish body to respond, and as a result, they were trapped into granulomas (Figure 3c). Many cysts in the liver induced growth retardation ( $0.5 \mathrm{gr}$ of body weight instead $4 \mathrm{gr}$ ), indicating the digenean metacercariae's apparent influence on the fish body condition. Our field study suggests that heavy infected small fish fingerlings were withdrawn from the fish population (Falk et al., 2020). However, juvenile fish with a few parasitic cysts did not demonstrate any signs of stress or weakness.

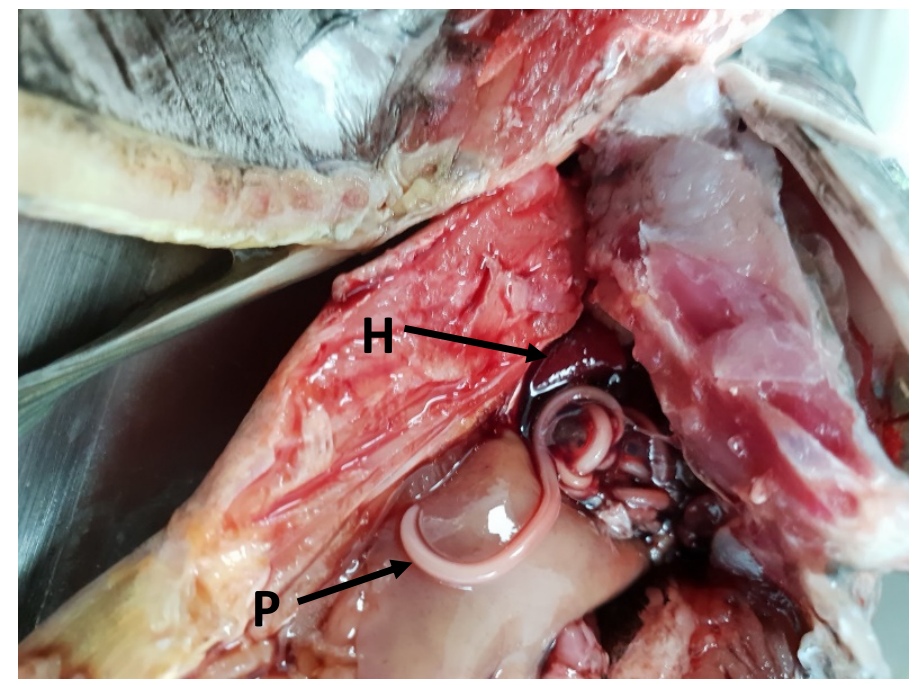

Figure 1 The Nematode in heart cavity. H-heart; P-parasitic nematode.

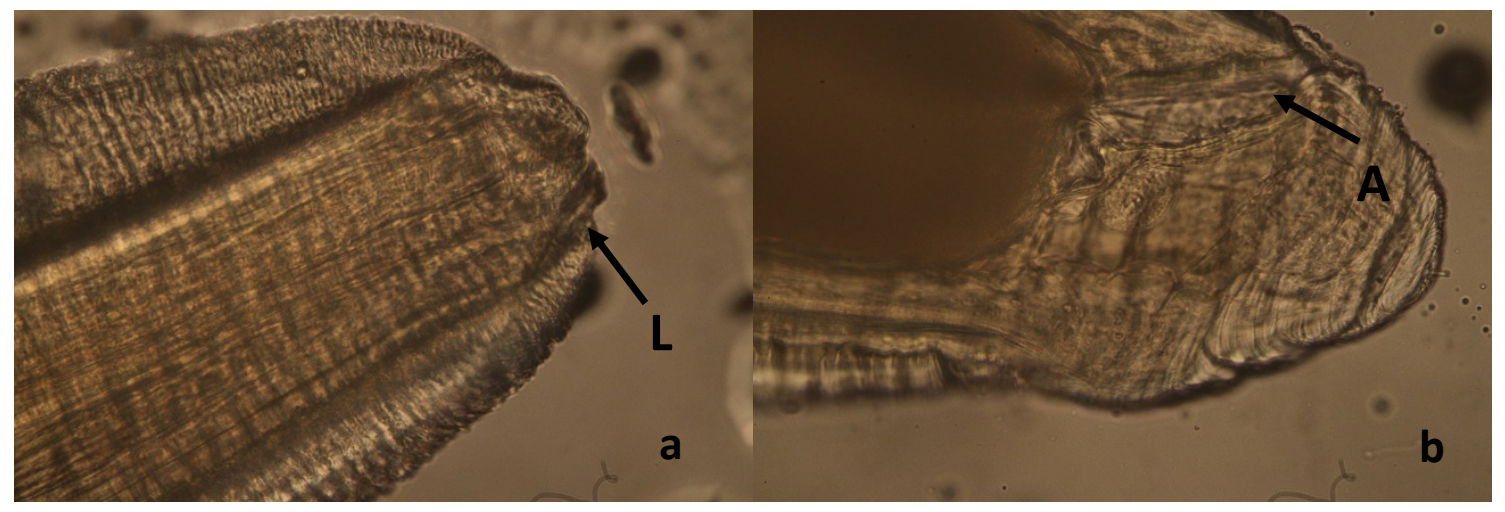

The Israeli Journal of Aquaculture - Bamidgeh • IJA.73.2021.1370552 


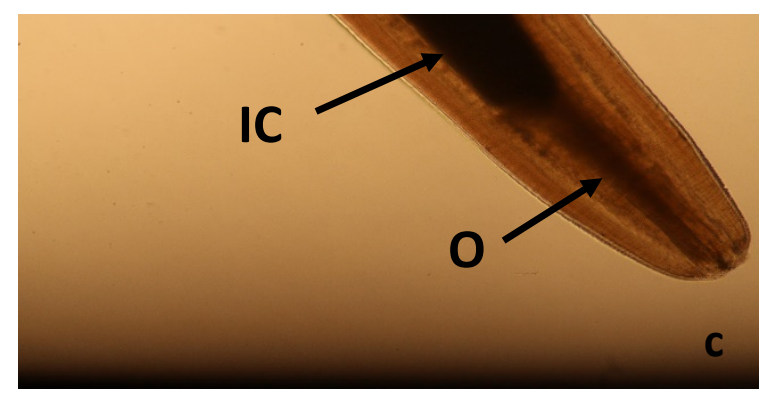

Figure 2 Light microscopy. a) Anterior end of parasite L- lips ( $x 40)$; b) Posterior end of parasite A- anus $(x 40) ; c)$ Anterior part of parasite IC-intestinal caecum O-esophagus (x10).

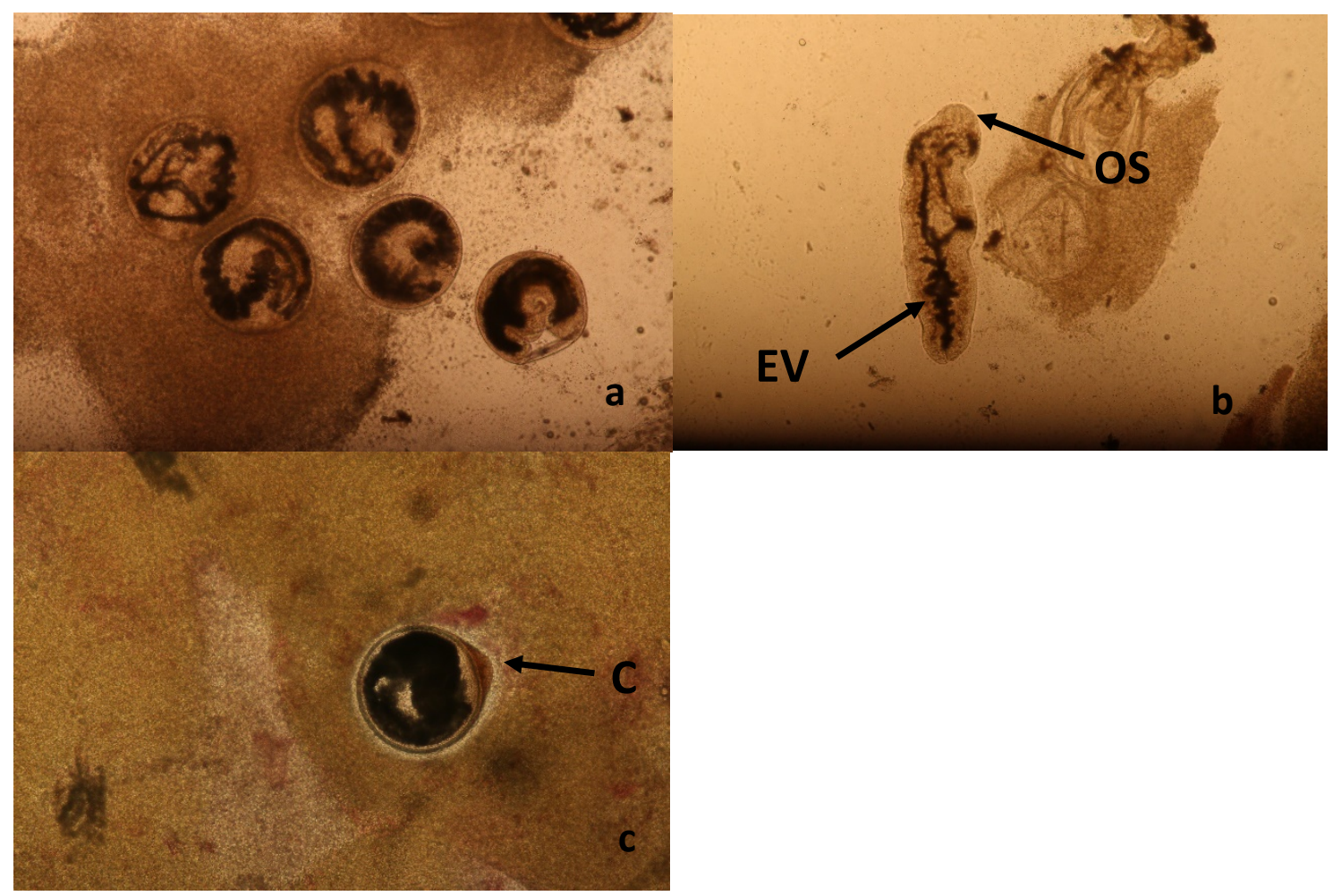

Figure 3 Light microscopy. a) Cysts of metacercaria in fish liver (X400); b) released parasite OSoral sucker EV-excretory vesicle $(x 40)$; c) Encapsulated dead parasite in fish liver C- granuloma (x400).

\section{Discussion}

Our studies found that these two helminths are not new in the existing list of parasites in Israeli fish farms or inland waters. From 1984 through 1991, infestation with this parasitic nematode was spread throughout all the fish farms in Israel. The infection level reached up to $100 \%$, with worms concentrated only in the pericardium cavity. Paperna defined this parasite larvae morphologically as Contracaecum multipapillatum and, with a staff of CFHL, investigated and established its whole life cycle (Bejerano, 1984, Landsberg, 1988). The second time infestation of this nematode larvae was reported in 1996, and only two farms were affected with a very low prevalence of parasites (unpublished data of CFHL). The third time when routine examination of tilapia revealed that most Beit She'an Valley farms were affected by a low nematode prevalence. Data on infection intensity in different years is shown in Table 1 (page 8, at the end of the article). As in previous cases, the worms did not induce visible damage and were not observed in other inner organs or subcutaneous muscles.

Unidentified digenean metacercaria N1 was found in the liver of tilapia in Lake Kinneret (the Sea of Galilee) during all the investigations conducted for 40 years (Paperna, 1964; Djikowski et al., 2003; Falk et al., 2020). Data of infection corresponding to years is shown in Table 2. Only a 
single case occurred in the fishponds during 2001, but the level of infection was neglectable. The appearance and prevalence of this parasite in summer 2020 were surprising to the new generation of Israeli fish farmers. Significant differences were found between farms in the prevalence average and the abundance average of the metacercaria $N 1$ (data are not shown). Further investigation into the definition of this parasite species is needed.

The emergence of these parasitic infections can be explained due to changes in management in fish farming. Israel is located between Europe and Africa on the major seasonal bird migration route. During bird migration, the control on parasites was achieved when pelicans were kept away from the ponds. The next step was the effective extermination of the free-living larval stages of parasites with Bromex 50 (weak organophosphorus compound). In the last six years, the Israeli regulations forbidden to disturb the migrating birds-of-prey in farms' fish ponds and the use of Bromex 50.

Unfortunately, no replacement measures to prevent the migrating birds-of-prey from introducing the parasites to the fish ponds or treatment against the nematode's larvae were offered by the Israeli authorities. At the same time, the regulations place the bird-of-prey species under protection (Elkin, 2019).

In conclusion, although these parasites are rare nowadays, if the appropriate measures are not taken, it might lead to the reappearance of old problems and the worsening of the situation.

Table 1 Infection-Intensity and prevalence of the Contracaecum.

\begin{tabular}{lcccc}
\hline Years & \multicolumn{3}{c}{ Location } \\
& $\begin{array}{c}\text { Lake Kinneret } \\
\text { Prevalence } \\
(\%)\end{array}$ & Intensity & $\begin{array}{c}\text { Prevalence } \\
(\%)\end{array}$ & Intensity \\
\hline 1964 & 0.1 & ND & - & - \\
$1982-1989$ & - & - & $10-100$ & $2-5$ \\
1996 & - & - & 3 & 2 \\
$2012-2014$ & ND & ND & - & - \\
$2020-2021$ & - & - & $0.8-2$ & $1-5$ \\
\hline ND - Not Determined. Intensity was counted from 1 (very low) to 5 (very high)
\end{tabular}

Table 2 Infection-Intensity and prevalence of the metacercaria N1.

\begin{tabular}{lcccc}
\hline Years & \multicolumn{4}{c}{ Location } \\
& $\begin{array}{c}\text { Lake Kinneret } \\
\text { Prevalence } \\
(\%)\end{array}$ & Intensity & $\begin{array}{c}\text { Prevalence } \\
(\%)\end{array}$ & Intensity \\
\hline 1964 & 83.5 & 3 & - & - \\
$1982-1984$ & 0.1 & 2 & - & - \\
2001 & 55 & 5 & 0.1 & 1 \\
$2012-2014$ & 3 & ND & - & - \\
$2020-2021$ & - & - & $10-100$ & $1-5$ \\
\hline ND - Not Determined. Intensity was counted from 1 (very low) to 5 (very high)
\end{tabular}

\section{Acknowledgements}

We thank the fish farmers of the Beit She'an Valley for their kind collaboration. 


\section{References}

Amare A., Alemayehu A., Aylate A., 2014.Prevalence of Internal Parasitic Helminthes Infected Oreochromis niloticus (Nile Tilapia), Clarias gariepinus (African Catfish) and Cyprinus carpio (Common Carp) in Lake Lugo (Hayke), Northeast Ethiopia. Journal of Aquaculture Research and Development V 5:3 pp1-5. http://dx.doi.org/10.4172/2155-9546.1000233

Bejerano I., 1984. Personal communication.

Castellanos J. A., Tangua A. R., Salazar L., 2017.Anisakidae nematodes isolated from the flathead grey mullet fish (Mugil cephalus) of Buenaventura, Colombia. International Journal for Parasitology: Parasites and Wildlife 6) 265e270. https://doi.org/10.1016/j.ijppaw.2017.08.001.

Dzikowski R., Diamant A., Paperna I., 2003. Trematode metacercariae of fishes as sentinels for a changing limnological environment. Diseases of Aquatic Organisms 55:145-150. https://doi.org/10.3354/dao055145

Elkin Z., 2019. Minister of Environmental Protection. Declaration of national parks, nature reserves, national sites and memorial sites (protected natural values). https://bit.ly/3kzwkZj

Falk R., Smirnov M., Ofek T., Cummings D., 2020 Parasitological Survey of Cichlidae in the Sea-of-Galilee. The Israeli Journal of Aquaculture - Bamidgeh IJA.72.2020.1123146 6 pages. http://doi.org/10.46989/001c.19012

Landsberg, J.H. (1988). Parasites and associated diseases of fish in warm water culture with special emphasis on intensification. In: Shilo, M., Sarig, S. (eds.) Fish culture in warm water systems: Problems and trends. CRC Press Inc. Boca Raton, FL, pp195-251. ISBN-10: 0849347432; ISBN-13: 978-0849347436

Lymbery A. J., Doupé R. G., Munshi M. A., Wong T., 2002. Larvae of Contracaecum sp. among inshore fish species of southwestern Australia. Diseases of Aquatic Organisms Vol. 51: 157-159. https://doi.org/10.3354/dao051157

Noga, E.J. 1996. Fish Disease: Diagnosis and Treatment. St. Louis, MO Mosby-Year Book, Inc. 1726. ISBN: $978-0-813-80697-6$

Noga E.J., 1996. Fish Disease: Diagnosis and Treatment. St. Louis, MO Mosby-Year Book, Inc. 17-26. ISBN: 978-0-813-80697-6

Paperna I., 1964. The Metazoan Parasite Fauna of Israel Inland Water Fishes. Israeli Journal of Aquaculture - Bamidgeh 16:1-66.

Paperna I., (1974). Larval Contracaecum in the pericardium of fishes from East African lakes. Proc. Helminthology Society Washington 41: 252.

Paperna I., 1991. Diseases Caused by Parasites in The

Aquaculture of Warm Water Fish. Annual Rev. of Fish Diseases pp. 26-27. https://doi.org/10.1016/0959-8030(91)90028-I

Paperna I., (1996) Parasites, Infections and diseases of fishes in Africa-an Update.

Technical Paper 31. Central Institute of Freshwater Aquaculture, Food and Agriculture Organization, United Nations, Rome.

Pekmezci G. Z., Yardimci B., 2019. On the occurrence and molecular identification of Contracaecum larvae (Nematoda: Anisakidae) in Mugil cephalus from Turkish waters. Parasitology Research 118:1393-1402. https://doi.org/10.1007/s00436-019-06278-x

Pronkina N. V., Spiridonov S. E., 2020. Third-stage juveniles of Contracaecum sp. (Anisakidae, Ascaridomorpha) from the round goby Neogobius melanostomus of the Black Sea. Russian Society of Nematologists p.45. https://doi.org/10.24411/0869-6918-2020-10004

Shamsi, S., Gasser, R., Beveridge, I., Shabani, A. A., (2008). Contracaecum pyripapillatum n. sp. and a description of C. multipapillatum (von Drasche 1882) from the Australian pelican, Pelecanus conspicillatus. Parasitology Research 103, 1031-1039. https://doi.org/10.1007/s00436008-1088-z

Valles-Vega I., Molina-Fernández D., Benítez R., 2017. Early development and life cycle of Contracaecum multipapillatum s.I. from a brown pelican Pelecanus occidentalis in the Gulf of California, Mexico. Diseases of Aquatic Organisms Vol. 125: 167-178. https://doi.org/10.3354/dao03147

Younis A.E., Saad A.I., Rabei J. M., 2017. The occurrence of Contracaecum sp. Larvae (Nematoda: Anisakidae) in four teleostean species from Lake Nasser, Egypt morphological and molecular studies. The Journal of Basic and Applied Zoology 78:9.1-13 pp. https://doi.org/10.1186/s41936-017-0012-4 